\title{
Relation of Pressor Responsiveness to Angiotensin II and Insulin Resistance in Hypertension
}

\author{
Cynthia L. Gaboury, ${ }^{*}$ Donald C. Simonson, ${ }^{*}$ Ellen W. Seely, ${ }^{*}$ Norman K. Hollenberg, ${ }^{\star}$ and Gordon H. Williams ${ }^{\star}$ \\ *Endocrine-Hypertension Division, ${ }^{\ddagger}$ Departments of Medicine and Radiology, Brigham and Women's Hospital and Harvard Medical \\ School, Boston Massachusetts 02115
}

\begin{abstract}
To test the hypothesis that the hypertension associated with insulin resistance is secondary to an altered responsiveness of the vasculature to pressor agents, we evaluated the relationship between insulin resistance and pressor responses to angiotensin II (AII) in 21 hypertensive (HT) and 8 normotensive (NT) subjects on both a high ( $200 \mathrm{meq})$ and a low (10 meq) sodium diet. When sodium balance was achieved, each supine fasting subject underwent an AII infusion at a rate of $3 \mathrm{ng} / \mathrm{kg}$ per min for $60 \mathrm{~min}$, with blood pressure monitored every $2 \mathrm{~min}$. On the next day under similar conditions, a euglycemic hyperinsulinemic clamp was performed, with plasma glucose clamped at $90 \mathrm{mg} / \mathrm{dl}$ for $120 \mathrm{~min}$. There was no significant relationship between the glucose disposal rate (M) or the insulin sensitivity index ( $M$ divided by the mean insulin level $[M / I]$ ) and blood pressure response to AII in the NTs, but a highly significant $(P<0.019)$ negative correlation $(r=-0.55)$ in the HTs. Furthermore, in eight lean HTs whose body mass index was identical to that observed in the NTs, the relationship was even more striking $(P<0.008 ; r=-0.85)$. The results on high and low salt diets were similar; however, the $M$ and M/I were significantly increased $(P<0.05)$ in the NTs but not HTs with sodium restriction.
\end{abstract}

In conclusion, HTs but not NTs display a striking correlation between pressor response to AII and insulin resistance. This relationship is independent of the level of sodium intake. Furthermore, sodium intake modifies insulin sensitivity in NTs but not HTs. These results strongly suggest that a primary change in pressor response to vasoactive agents in insulin-resistant subjects can contribute to their elevated blood pressure. (J. Clin. Invest. 1994. 94:22952300) Key words: insulin resistance - pressor response • hypertension • sodium intake • angiotensin II

\section{Introduction}

Patients with essential hypertension often have obesity and/or non-insulin-dependent diabetes mellitus (NIDDM). ' Although

Address correspondence to Gordon H. Williams, M.D., Endocrine-Hypertension Division, Brigham and Women's Hospital, 221 Longwood Avenue, Boston, MA 02115.

Received for publication 27 December 1993 and in revised form 2 August 1994.

1. Abbreviations used in this paper: AII, angiotensin II; M, glucose disposal rates; M/I, insulin sensitivity index; NIDDM, non-insulindependent diabetes mellitus.

J. Clin. Invest.

(c) The American Society for Clinical Investigation, Inc.

0021-9738/94/12/2295/06 \$2.00

Volume 94, December 1994, 2295-2300 all three conditions are common, their degree of association is greater than what one would predict based on their individual frequency in the general population (1-5). This association has lead some investigators to postulate that insulin resistance is the cause for the hypertension. Several (1-8) but not all (9) studies have reported that some patients with essential hypertension have insulin resistance beyond that which could be accounted for with concomitant NIDDM or obesity.

Documentation of an association between insulin resistance and/or hyperinsulinemia and essential hypertension has been relatively straightforward. Determining whether it causes or contributes to the hypertension has been controversial. Equally controversial, if indeed insulin resistance contributes to hypertension, is determining the mechanism by which it does so. Most proposals have revolved around either a defect in sodium handling by the kidney, induced by the state of insulin resistance, or an increased activation of the adrenergic nervous system (1-8). A third possibility is an altered responsiveness of the vascular smooth muscle to pressor agents.

The purpose of the present study was to evaluate the validity of this third hypothesis. Pressor responsiveness to angiotensin II (AII) and glucose disposal rates, as determined during a euglycemic insulin clamp, was assessed in both normotensive and hypertensive subjects. Because a difference was observed between normotensive and hypertensive patients, we also have evaluated whether the obesity that occurs with increased frequency in hypertensives could contribute to this difference. Finally, to determine whether the responses were affected by changes in salt intake, the studies were repeated on a low salt diet.

\section{Methods}

\section{Subjects}

21 hypertensive and 8 normotensive subjects form the basis of this report. Not all of the hypertensive subjects completed all parts of the protocol. Some of the results in the normotensive subjects have been reported previously (10). The hypertensive patients ranged in age from 28 to $55 \mathrm{yr}$, and the normotensives ranged in age from 21 to $48 \mathrm{yr}$. Secondary causes of hypertension were excluded by requiring normal levels of blood urea nitrogen, creatinine, potassium, 24-h urine norepinephrine, epinephrine, dopamine, vanilly/mandelic acid (VMA), metanephrine, and urinalysis. Where indicated, all subjects also had a 2-h postprandial glucose of $<140 \mathrm{mg} / \mathrm{dl}$ and normal physical examinations, except for the increased blood pressure in the hypertensive patients. The protocol was approved by the Committee for the Protection of Human Subjects at the Brigham and Women's Hospital, and signed consent forms were obtained in each case. All studies were performed on the General Clinical Research Center at the Brigham and Women's Hospital.

\section{Protocol}

In each subject, pressor responses to AII and insulin sensitivity were assessed on both a high and a low sodium intake. Each subject was admitted to the Clinical Research Center and placed on a $100 \mathrm{meq}$ potassium, $1,000 \mathrm{mg}$ calcium isocaloric diet containing either 200 or 
10 meq of sodium. Studies were performed on the third day after initiation of the high salt and usually on the fifth day after the start of the low salt diet. The actual timing was determined by when sodium equilibrium had been established ( $<20 \mathrm{meq} / 24-\mathrm{h}$ urine or $>150 \mathrm{meq} /$ 24-h urine).

When sodium balance was achieved, the patients remained supine and fasting overnight. On the next morning, blood pressure was measured during a 60 -min control period followed by a 60 -min infusion of AII ( $3 \mathrm{ng} / \mathrm{kg}$ per $\mathrm{min}$ ). Blood pressure was monitored continuously with an indirect recording sphygnomometer (Dinamapp $\left.{ }^{\circledR}\right)$. On the day after the AII infusion, a euglycemic insulin clamp was performed. $\mathrm{Pa}-$ tients were again kept supine and fasting overnight.

In some subjects, both the high and low salt studies were performed in the same admission. Under those circumstances, the high salt diet was usually administered first. In the normotensive subjects and in other hypertensive patients, the studies were performed on separate admissions, and the order of diets was randomized.

\section{Techniques}

Euglycemic hyperinsulinemic clamp. Each subject received a 120-180min euglycemic insulin clamp, as previously reported (10-13). In brief, after an overnight fast, an indwelling venous catheter was placed in an antecubital vein, through which glucose and insulin were infused. A second catheter was placed in a dorsal hand vein retrogradely for blood sampling. This hand was kept in a warming box, heated to $70^{\circ} \mathrm{C}$ to ensure that the venous blood was arterialized (14). After the collection of baseline samples, a primed continuous infusion of crystalline insulin was administered at a rate of $40 \mathrm{mU} / \mathrm{M}^{2}$ per min. Plasma glucose was measured at 5-min intervals and insulin was measured at 30-min intervals. The glucose level was maintained at $\sim 90 \mathrm{mg} / \mathrm{dl}$ by a variable infusion of $20 \%$ dextrose in water using a negative feedback algorithm (11). The amount of glucose infused $\left(\mathrm{mg} / \mathrm{M}^{2}\right.$ per $\mathrm{min}$ ) during the last 60-120 min of the clamp is the glucose disposal rate (M). This value divided by the mean serum insulin levels (I) is an index of insulin sensitivity ( $\mathrm{M} / \mathrm{I}$ in $\mathrm{mg} / \mathrm{M}^{2}$.min per $\left.\mu \mathrm{U} / \mathrm{ml}\right)$.

Biochemical analyses. Plasma glucose was measured by the glucose oxidase method using a glucose reflectometer (Lifescan, Mountain View, CA). Sodium and potassium were measured using a flame photometer, creatinine was measured in the urine by an autoanalyzer technique, and insulin, plasma renin activity, and aldosterone were measured by radioimmunoassay techniques as previously described (15-17). Plasma norepinephrine levels were measured by a modification of the Peuler and Johnson technique, as previously reported (18).

Statistical techniques. All data were analyzed using a CLINFO data processing system. Means were determined and the index of dispersion as reported herein are the standard errors. Statistical comparisons were made using unpaired and paired $t$ statistics for normally distributed data and Fisher's exact test for data that were not normally distributed. When multiple comparisons were made to a single control, Dunnett's correction was used. Significance level was $P<0.05$ unless otherwise stated.

\section{Results}

Demographic information on the hypertensive and normotensive subjects is presented in Table I. Blood pressure was measured supine after the subjects had been hospitalized several days. There were no significant differences besides blood pressure, except the hypertensive patients were heavier than the normotensive patients and the gender distribution was different. However, a subset of the hypertensive patients who had a body mass index indistinguishable from the normotensive subjects could be identified (Table I).

Glucose disposal rates. The glucose disposal rates (M) in the hypertensive patients were significantly lower than in the normotensive subjects. This was true in subjects on the low sodium diet, whether the total $(P=0.001)$ or only the lean $(P$ $=0.02$ ) hypertensives were used in the comparison. Subjects
Table I. Demographic Data on Studied Subjects

\begin{tabular}{lccc}
\hline & $\begin{array}{c}\text { Total } \\
\text { hypertensives }\end{array}$ & $\begin{array}{c}\text { Lean } \\
\text { hypertensives }\end{array}$ & Normals \\
\hline Number & 21 & 8 & 8 \\
Male/female & $12 / 9$ & $4 / 4$ & $8 / 0$ \\
Age (y) & $45 \pm 2$ & $41 \pm 3$ & $36 \pm 5$ \\
Body mass index (kg/m $\left.{ }^{2}\right)$ & $26.3 \pm 1.0^{*}$ & $21.7 \pm 0.9$ & $21.0 \pm 0.6$ \\
Plasma [K ${ }^{+}$] (mEq/liter) & $4.1 \pm 0.1$ & $4.0 \pm 0.1$ & $4.2 \pm 0.1$ \\
Low salt supine plasma & & & \\
$\quad$ Aldosterone (ng/dl) & $21 \pm 2 *$ & $27 \pm 4$ & $37 \pm 5$ \\
$\quad$ Renin activity (ng/ml per h) & $2.0 \pm 0.2^{*}$ & $2.3 \pm 0.3 *$ & $4.1 \pm 0.6$ \\
& & &
\end{tabular}

$* P<0.05$ significantly different from normals.

studied on the high sodium diet demonstrated similar differences (total hypertensives, $P=0.01$; lean hypertensives, $P$ $=0.05)$. These differences persisted even if the glucose disposal rate was normalized to the mean insulin level during the clamp (M/I) ( $P$ ranged between 0.001 and 0.03 ) (Table II). There were no differences in the mean insulin level achieved during the clamp between the several groups (Table II). Mean glucose during the clamp ranged from 91 to $94 \mathrm{mg} / \mathrm{dl}$ in the individual groups, not significantly different from each other or fasting glucose levels (Table II).

Correlation between glucose disposal rate and blood pressure. In the normotensive individuals on a high salt diet, there was no significant relationship between $\mathrm{M}$ or its ratio $\mathrm{M} / \mathrm{I}$ during the clamp and the blood pressure response to a $3 \mathrm{ng} / \mathrm{kg}$ per min AII infusion ( $r=-0.017 ; P=0.969$ for $\mathrm{M} / \mathrm{I}$ ) (Fig. 1, Table II). In contrast, in the hypertensive subjects, there was a highly significant $(P<0.019)$ correlation between these two parameters $(r=-0.55)$. To determine the impact of obesity on these relationships, the results in eight lean hypertensive patients were evaluated separately. These patients had a body mass index identical to that of the normotensive subjects (Table I). Again, there was a striking correlation between the systolic blood pressure response to AII and the $\mathrm{M}$ or $\mathrm{M} / \mathrm{I}(P=0.008)$. Indeed, if anything, the relationship was more striking in the lean hypertensives than in the total hypertensive population ( $r$ $=-0.85)$ (Fig. 2). A similar relationship was observed for diastolic blood pressure.

To ascertain whether the responses were sensitive to salt intake, the studies were repeated on a low sodium diet (Fig. 3 ). In the normotensive subjects, again there was no correlation. However, in the hypertensive patients, a correlation again existed, as was observed when the patients were on the more usual normal intake (high salt) $(P<0.02, r=-0.53)$.

Influence of sodium intake on insulin sensitivity index. Dietary sodium intake did not produce a significant change in $\mathbf{M}$, fasting insulin levels, or $M / I$ in the hypertensive patients, whether the data from the total or only the "lean" hypertensives were analyzed (Table II). This was in contrast to the normotensive subjects, whose $\mathrm{M} / \mathrm{I}$ fell from $5.92 \pm 0.45$ to $4.98 \pm 0.42$ ( $P$ $<0.05$ ) (Table II) when sodium intake was increased. The $M$ also fell significantly $(P<0.01)$. These differences were not associated with differences in plasma epinephrine and norepinephrine, or urinary potassium or sodium excretion on the day before study, as they were equivalent on the two study days for all subjects (Table II).

Impact of sodium intake on blood pressure. In the total 
Table II. Impact of Sodium Intake on Physiological and Biochemical Data in Normotensive and Hypertensive Subjects*

\begin{tabular}{|c|c|c|c|c|c|c|}
\hline & \multicolumn{2}{|c|}{ Total hypertensives } & \multicolumn{2}{|c|}{ Lean hypertensives } & \multicolumn{2}{|c|}{ Normotensives } \\
\hline & High salt & Low salt & High salt & Low salt & High salt & Low salt \\
\hline Systolic blood pressure (mmHg) & $143 \pm 4$ & $131 \pm 3$ & $135 \pm 6$ & $125 \pm 4$ & $116 \pm 3$ & $111 \pm 3$ \\
\hline Diastolic blood pressure $(\mathrm{mmHg})$ & $89 \pm 2$ & $83 \pm 1$ & $86 \pm 3$ & $80 \pm 2$ & $63 \pm 2$ & $64 \pm 2$ \\
\hline Fasting insulin $(\mu \mathrm{U} / \mathrm{ml})$ & $9 . \pm 1$ & $11 \pm 2$ & $6 \pm 2$ & $6 \pm 2$ & $5 \pm 1$ & $5 \pm 2$ \\
\hline Fasting glucose (mg/dl) & $93 \pm 2$ & $93 \pm 3$ & $97 \pm 3$ & $91 \pm 5$ & $97 \pm 2$ & $96 \pm 2$ \\
\hline Glucose infusion rate $\left(\mathrm{mg} / \mathrm{M}^{2} \mathrm{~min}\right)$ & $198 \pm 18$ & $201 \pm 21$ & $225 \pm 18$ & $241 \pm 28$ & $276 \pm 19$ & $334 \pm 24$ \\
\hline Clamp insulin $(\mu \mathrm{U} / \mathrm{ml})$ & $75 \pm 4$ & $81 \pm 4$ & $68 \pm 5$ & $72 \pm 6$ & $57 \pm 1$ & $61 \pm 3$ \\
\hline Glucose infusion rate/mean/insulin & $2.86 \pm 0.32$ & $2.60 \pm 0.33$ & $3.52 \pm 0.35$ & $3.52 \pm 0.41$ & $4.98 \pm 0.42$ & $5.92 \pm 0.45$ \\
\hline Urine sodium (meq/d) & $180 \pm 6$ & $11 \pm 1$ & $183 \pm 10$ & $9 \pm 1$ & $160 \pm 7$ & $8 \pm 2$ \\
\hline Urine potassium (meq/d) & $72 \pm 3$ & $72 \pm 3$ & $71 \pm 6$ & $71 \pm 5$ & $78 \pm 4$ & $79 \pm 4$ \\
\hline Plasma epinephrine (pg/ml) & $29 \pm 5$ & $52 \pm 16$ & $21 \pm 7$ & $39 \pm 13$ & $33 \pm 11$ & $29 \pm 7$ \\
\hline Plasma norepinephrine $(\mathrm{pg} / \mathrm{ml})$ & $203 \pm 31$ & $274 \pm 36$ & $193 \pm 54$ & $231 \pm 54$ & $273 \pm 56$ & $307 \pm 85$ \\
\hline
\end{tabular}

* See text for significant differences.

hypertensive population, the mean change in blood pressure was $12 \pm 2 / 7 \pm 1 \mathrm{mmHg}(P<0.05$ for mean blood pressure, Wilcoxon Rank Sum test) when the diet was changed from low to high salt. In contrast, in the normotensive subjects, no significant changes occurred $(5 \pm 2 / 0 \pm 1 \mathrm{mmHg}$ ) (Table II). The blood pressure responses to AII were greater in the hypertensive than in the normotensive subjects, whether on the low $(P<0.001$, Fisher's exact test $)$ or the high $(P=0.062$, Fisher's exact test) salt diet (Fig. 4). Although the blood pressure responses of the lean hypertensives were somewhat less than the total hypertensive group, these subjects were still more responsive to AII than the normotensive individuals when sodium restricted $(P<0.025$, Fisher exact test). Furthermore, sodium restriction significantly reduced $(P<0.04$, Wilcoxon Rank Sum test) the pressor responses to AII in normal subjects, but not in hypertensive subjects. Not only was there a significant difference in the blood pressure response to a change in sodium intake in hypertensives than normotensives, but there was also a significant difference in the correlation between $M$ or $M / I$

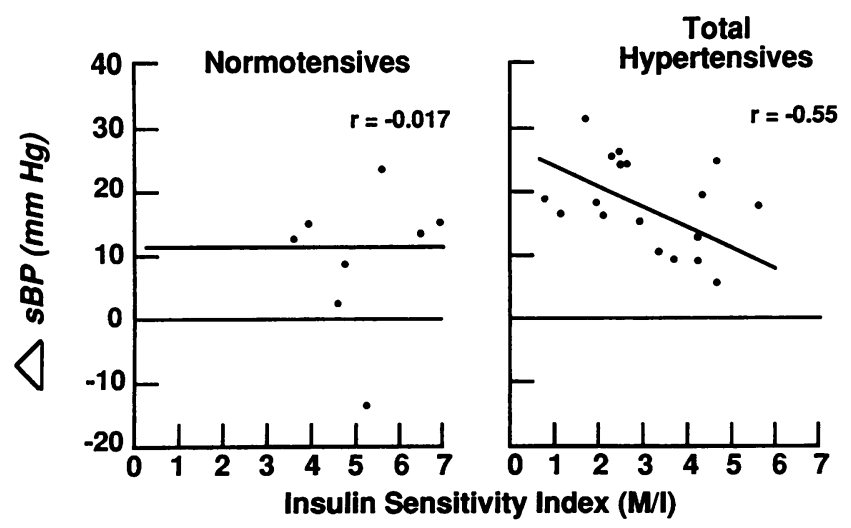

Figure 1. Correlation between $\mathrm{M} / \mathrm{I}$ and pressor response to AII. Pressor responsiveness is depicted as change in systolic blood pressure in response to $3 \mathrm{ng} / \mathrm{kg}$ per min infusion of AII. 18 hypertensive and 8 normotensive patients were studied. The correlation in the hypertensive patients was highly significant $(P<0.019)$. There was also a significant correlation between $\mathrm{M}$ and pressor responses to AII, but only in the hypertensive subjects $(r=0.51 ; P<0.03)$. No relationship existed in the normotensives $(r=0.15 ; P=0.73)$. and the blood pressure response to sodium loading. However, this reached statistical significance only in the lean hypertensives $(r=-0.73, P=0.03$, using $\mathrm{M} / \mathrm{I}$ and $r=-0.86, P$ $<0.006$ using M) (Fig. 5).

Finally, we assessed the relationship between the basal control blood pressure levels and the pressor response to angiotensin II or the $M / I$. When the hypertensive patients were sodium restricted, there was a highly significant correlation between the increment in mean blood pressure in response to AII infusion and the basal diastolic pressure $(r=0.65, P<0.002)$ or mean blood pressure $(r=0.60, P<0.006)$, as measured the day before the AII infusion. There was also a marginally significant correlation between the basal mean blood flow and the M/I ( $r$ $=-0.445, P=0.056$ ), but not with $M$. However, in the sodiumrestricted, lean hypertensive subjects, there was a highly significant correlation between basal mean blood pressure and $\mathrm{M}$ / I $(r=-0.83, P=0.011)$ and $\mathrm{M}(r=-0.75, P=0.032)$. In contrast, when the hypertensive subjects (total or lean) were sodium loaded, there was no significant correlation between $M$ / I or $\mathbf{M}$ and the basal blood pressure, and there was only a

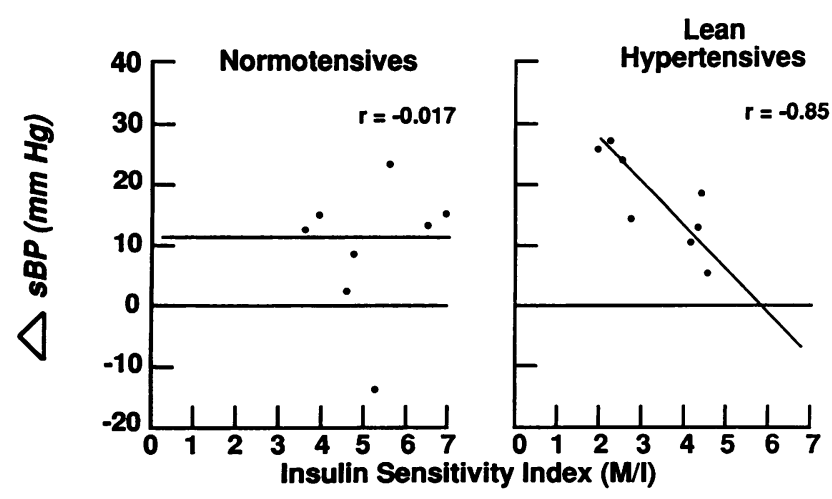

Figure 2. Correlation between insulin sensitivity index and pressor response to AII in lean hypertensive patients. Hypertensive patients had similar body mass indexes as normotensive subjects. The regression relationship between systolic blood pressure response to AII and M/I was highly significant $(P<0.008)$. Similar relationships existed with mean and diastolic blood pressure. When $M$ was used as the independent variable, a similar relationship existed (e.g., for correlation with mean blood pressure responses $r=0.70 ; P<0.05$ ). 


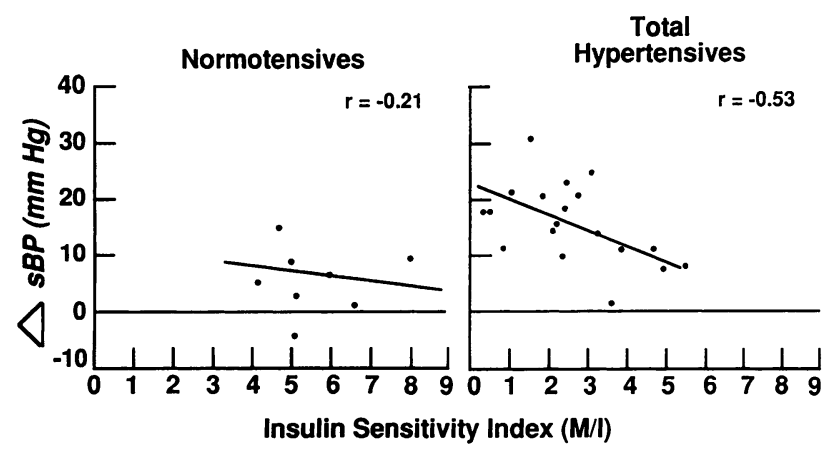

Figure 3. Correlation between $\mathrm{M} / \mathrm{I}$ and pressor response to $\mathrm{AII}$ in individuals on a low sodium diet. 21 hypertensive patients and 8 normotensive subjects were studied. The correlations was highly significant in the hypertensive patients $(P<0.02)$, but not in the normotensive subjects. The correlations of the systolic blood pressure response to AII to $\mathrm{M}$ were similar (hypertensives: $r=-0.42, P=0.07$; normotensives: $r=-0.21, P=0.63$ ).

marginally significant relationship between the increment in diastolic blood pressure response to AII and the mean basal blood pressure $(r=0.45, P=0.07)$.

\section{Discussion}

This study has confirmed two observations in patients with essential hypertension, enhanced pressor responsiveness to AII and a striking prevalence of insulin resistance, and has linked them. There was a strong negative correlation between the degree of insulin sensitivity and the enhanced pressor response. This association was evident in the essential hypertensives as a group and, particularly, in lean hypertensives. Moreover, restriction of sodium intake did not change this primary relationship. Over the range of either glucose disposal rates or insulin sensitivity indexes seen in normal subjects, there was no relationship between either variable and the pressor response to AII, whether or not dietary sodium intake was restricted. Indeed, there was no reason to expect such a relationship. In contrast, in the patients with hypertension, because of the negative corre-

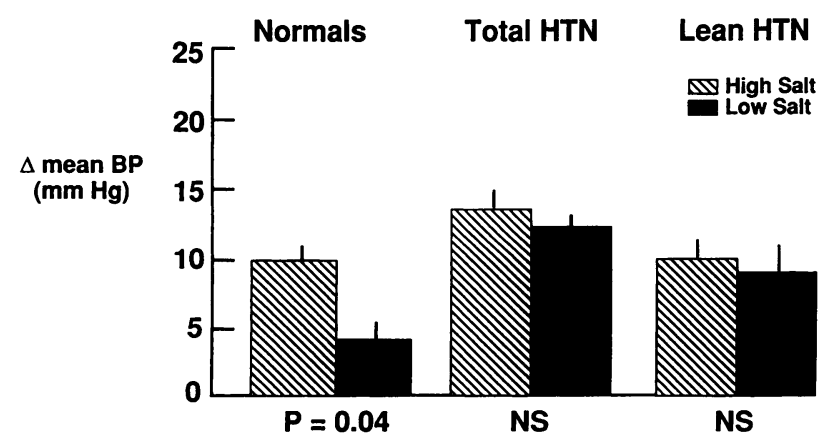

Figure 4. Relationship between the blood pressure response to AII and salt intake. Increment in mean blood pressure with a $3 \mathrm{ng} / \mathrm{kg}$ per min AII infusion in 8 normotensive subjects and 18 total and 8 lean hypertensive patients is presented. The hypertensive patients had a greater blood pressure response than did the normotensive subjects, both on the high $(P=0.062)$ and the low $(P<0.001)$ salt intakes. Furthermore, only in the normotensive subjects did sodium intake significantly modify pressor responses $(P<0.04)($ mean \pm SEM $)$.

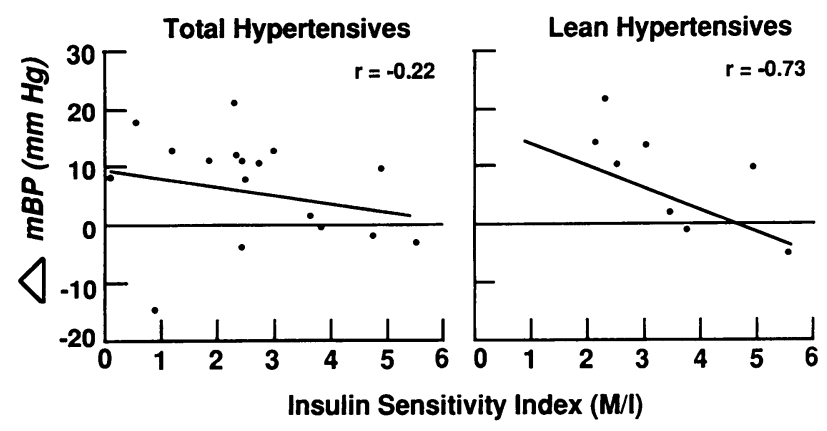

Figure 5. Correlation between $\mathrm{M} / \mathrm{I}$ and the blood pressure response to changes in sodium intake. 17 patients comprised the total hypertensive group, with 8 in the lean hypertensive group. There was no correlation between $\mathrm{M} / \mathrm{I}$ and change in systolic blood pressure in response to sodium intake in the total hypertensive patients, but this was observed in the lean hypertensive subjects $(P<0.03)$. In contrast, no correlation existed in the normotensive subjects (data not shown). The correlation with $\mathrm{M}$ was equally significant in the lean hypertensives $(r=-0.86$; $P<0.006$ ).

lation between glucose disposal and the pressor response to AII, the largest pressor responses occurred in patients with the lowest glucose disposal rates or insulin sensitivity indexes, i.e., those who are the most insulin resistant. It is still unclear which is the dependent and which is the independent variable. In the range of glucose disposal that overlapped with the normotensive subjects, i.e., > 3.5, the pressor response to AII was normal in most of the hypertensive subjects. Because of the more frequent occurrence of obesity in hypertensive patients, a subanalysis was performed in the lean hypertensives. In this subset, an even more striking negative correlation was found. Again, the pressor response in those subjects with the most normal glucose disposal rates was essentially normal. Finally, there was a highly significant correlation between the baseline blood pressure and the pressor response to AII in hypertensive, but not normotensive, subjects studied on the low sodium intake. A more modest effect was observed in those subjects studied on a high sodium intake. There was also a modest correlation between the $\mathrm{M} / \mathrm{I}$ and the basal blood pressure in sodium-restricted subjects. Again, the results were more striking in the lean hypertensives, whether the correlation was with MI $(r=-0.83, P=0.011)$ or with $\mathrm{M}(r=-0.75, P=0.032)$. This association also disappeared when the subjects were on a high sodium intake.

Interpreting the relevance of the association between insulin resistance and hypertension has been difficult because a substantial fraction of the essential hypertensive population is obese. However, several (1-8) studies have now reported that some patients with essential hypertension have insulin resistance beyond that which can be attributed to the concomitant presence of NIDDM or obesity. For example, Ferrannini et al. (8) documented insulin resistance in hypertensives with a body mass index of 26, similar to that in the total hypertensives in the present study. However, this finding has not been universal (9), and it may vary depending on the ethnic background, degree of obesity, and whether one studies normotensive or hypertensive subjects (19-21). The results of the present study cannot be affected by these confounding variables because patients with NIDDM were excluded. Second, the relationship between pressor responsiveness and insulin resistance existed even in subjects whose body mass index was similar to normotensive subjects $\left(\sim 21 \mathrm{~kg} / \mathrm{M}^{2}\right)$. Finally, all the subjects were Caucasian. 
Thus, this study does not provide information concerning whether a similar relationship would exist in other ethnic or racial groups.

A variety of techniques has been used to define insulin resistance. The most quantitative method is the euglycemic insulin clamp technique $(11,14)$, the approach used in the present study. Indeed, the relationship noted in this study would have been missed if a less sensitive approach to assess the insulin resistance had been used, i.e., the relationship between fasting glucose and insulin levels $(22,23)$.

What is the likely mechanism to explain the correlations observed in this study? The two most commonly cited mechanisms as to how insulin resistance can induce hypertension are a change in sodium handling by the kidney resulting in volume expansion or an increased activation of the adrenergic nervous system $(1-8)$. Neither of these mechanisms appear to be a likely explanation of our results for several reasons. First, to assess pressor responsiveness, we used exogenously administered AII. There is little evidence to suggest activating the adrenergic nervous system enhances the pressor response to AII. Second, although there is substantial evidence that volume expansion increases pressor responsiveness to AII, there is mixed evidence supporting this as the mechanism that underlies our findings. The first point against this mechanism is the fact that the effect was observed on both high and low sodium intakes. Second, there was no significant correlation of the change in blood pressure with change in salt intake (salt sensitivity ) and the degree of insulin resistance in the total hypertensive group, but this was observed in the lean subjects. However, the number of subjects studied is small. Thus, the degree of confidence in excluding a beta error is limited. In partial support, the plasma renin activity levels were lower in the hypertensive patients compared with the normotensive subjects, an observation that would be anticipated if the hypertensive patients had been volume expanded. Thus, although the present study cannot specifically exclude a direct effect of insulin modifying sodium reabsorption, producing a relative volume-expanded state and enhancing pressor responsiveness secondarily, the preponderance of evidence would make this possibility unlikely in these patients. A third possible mechanism for the role of insulin resistance in hypertension is a change in insulin-mediated vasodilatation. Baron and Brechtel (24) have suggested that insulin's vasodilator effect is blunted in obese subjects. Thus, they proposed that it is the resistance of the vascular smooth muscle to insulin's vasodilatory properties that leads to the development of hypertension. Unfortunately, there is little information available from the present study to assess this possibility, because no nonspecific vasodilator was used as a control, and the hypertensive patients obviously had a higher resting blood pressure than did the normotensive subjects.

Another intriguing possibility to explain the relationship between insulin resistance and hypertension is that insulin increases the responsiveness of the vascular smooth muscle to pressor agents. This possibility is supported by at least four considerations: $(a)$ a raised cytosolic calcium level induces insulin resistance, at least in adipocytes (25-27); (b) hypertension is associated with increased intracellular calcium levels (28-31); (c) a substantial fraction of the hypertensive population has enhanced vascular responsiveness (32); and ( $d$ ) AII itself promotes a rise in cytosolic calcium $(33,34)$. Thus, pressor responses to AII may be closely correlated with the degree of insulin resistance. Draznin and colleagues have documented that an increase in cytosolic free calcium reduces adipocyte sensitivity to insulin in both rats and humans (25-27). For their study, insulin sensitivity was determined by 2 -deoxyglucose metabolism. This is not an obligatory requirement for insulin resistance, as demonstrated by Kelly et al. (35), where insulin resistance was not always correlated with raised cytosolic calcium levels in adipocytes. However, of importance to the concept that hyperinsulinemia can actually contribute to increased cytosolic calcium is the direct effect of insulin on stimulating the calcium pump (calcium ATPase) (36, 37 ). Thus, a cell that has reduced insulin sensitivity would presumably have a reduced activity of the major transport process to pump calcium out of the cell, resulting in an increase in cytosolic calcium levels. Although cytosolic calcium levels were not measured in vascular smooth muscle cells in these patients, it is intriguing to speculate that the changes observed may be secondary to this insulin-mediated effect, as has been suggested by in vitro studies (38).

Do the differences between normotensive and hypertensive subjects in these relationships apply to all hypertensives or only to a subset? Unfortunately, the sample size was too small to perform meaningful subgroup analyses in, e.g., low and high renin patients or modulators and nonmodulators (32).

Finally, there is the intriguing observation of the impact of the level of sodium intake on the degree of insulin resistance in normotensive versus hypertensive subjects. We have previously reported that normotensive subjects have a reduced insulin sensitivity when placed on a high sodium intake (10). The mechanism responsible for this sodium-mediated change in insulin sensitivity is uncertain. One possibility is related to the observation reported by Sechi and colleagues (39). In their study, Sprague-Dawley rats were placed on a very high or low sodium chloride intake for $14 \mathrm{~d}$. The number of renal insulin receptors and the mRNA for the insulin receptor in the kidney were reduced in the animals maintained on a high sodium intake. Whether a similar mechanism exists in humans is uncertain. However, if so, this would suggest that the "insulin resistance", induced by salt loading is actually an appropriate adaptive response to reduce the number of insulin receptors in the kidney, thereby reducing renal sodium retention. In contrast, hypertensive patients studied on an identical protocol demonstrated no such effect. Several important caveats result from these observations: $(a)$ the contribution insulin resistance may make to the hypertensive process in some patients could be related to the absence of a sodium-mediated effect on insulin sensitivity potentially secondary to a defect in the regulation of the insulin receptor by dietary sodium; and $(b)$ in evaluating the degree of insulin sensitivity in normotensive and hypertensive subjects, one needs to control dietary sodium intake. Ideally, a low sodium diet would work best because insulin resistance is minimized in the normotensive subjects, but it remains unchanged in the hypertensive subjects.

In summary, hypertensive but not normotensive subjects display a striking correlation between the degree of pressor responsiveness to AII and the degree of insulin resistance. This relationship exists whether the subjects are studied on a high or low sodium intake, and it is present even when hypertensive and normotensive subjects with similar body mass indexes are compared. Furthermore, in hypertensive, but not in the normotensive, subjects, there was a significant correlation between the basal blood pressure and the pressor response to AII and the $\mathrm{M}$ or $\mathrm{M} / \mathrm{I}$, which was most easily appreciated when the subjects were studied on a low sodium intake. Finally, changing the 
level of sodium intake only modifies insulin sensitivity in normotensive subjects. Thus, the results of this study strongly suggest that a primary change in vascular responsiveness to pressor agents in insulin-resistant subjects can contribute to their elevated blood pressure independent of any renal or adrenergic nervous system effects of the insulin-resistant/hyperinsulinemic state.

\section{Acknowledgments}

We acknowledge the support of the Dietary and Nursing staffs of the General Clinical Research Center and the Administrative staff of the Endocrine-Hypertension Division, particularly Ms. Barbara Smith, for their assistance in the conduct of this study and preparation of this report.

Personnel involved in this study were in part supported by grants from the National Institutes of Health, HL-076091, HL-07609, and DK43505 , and grants from the American Diabetes Association. The studies were conducted on a Clinical Research Center supported by a grant from the National Center for Research Resources (RR-02635), and the results were analyzed using a data management system supported by the same grant.

\section{References}

1. Reaven, G. M., and B. B. Hofman. 1989. Hypertension as a disease of carbohydrate and lipoprotein metabolism. Am. J. Med. 87:2S-6S.

2. Pollare, T., H. Lithell, I. Selinus, and C. Berne. 1989. Sensitivity to insulin during treatment with atenolol and metoprolol: a randomized, double-blind study of effects on carbohydrate and lipoprotein metabolism in hypertensive patients. Br. Med. J. 298:1152-1157.

3. Laakso, M., H. Sarlund, and L. Mykkanen. 1989. Essential hypertension and insulin resistance in noninsulin-dependent diabetes. Eur. J. Clin. Invest. 19:518-526.

4. Halkin, H., M. Modan, M. Shefi, and S. Almog. 1988. Altered erythrocyte and plasma sodium and potassium in hypertension: a facet of hyperinsulinemia. Hypertension (Dallas). 11:71-77.

5. DeFronzo, R. A., and E. Ferrannini. 1991. Insulin resistance: a multifaceted syndrome responsible for NIDDM, obesity, hypertension, dyslipidemia, and atherosclerotic cardiovascular disease. Diabetes Care. 14:173-194.

6. Shen, D. C., S. M. Shieh, M. M. Fuh, D. A. Wu, Y. D. Chen, and G. M. Reaven. 1988. Resistance to insulin-stimulated glucose uptake in patients with hypertension. J. Clin. Endocrinol. \& Metab. 66:580-583.

7. Pollare, T., H. Lithell, and C. Berne. 1990. Insulin resistance is a characteristic feature of primary hypertension independent of obesity. Metabolism. 39:167174.

8. Ferrannini, E., G. Buzzigoli, R. Bonadonna, M. A. Giorico, M. Oleggini, L. Graziadei, R. Pedrinelli, L. Brandi, and S. Bevilacqua. 1987. Insulin resistance in essential hypertension. N. Engl. J. Med. 317:350-357.

9. Mbanya, J., T. H. Thomas, R. Wilkinson, K. G. Alberti, and R. Taylor. 1988. Hypertension and hyperinsulinemia: a relation in diabetes but not essential hypertension. Lancet. ii:733-734.

10. Donovan, D. S., C. G. Solomon, E. W. Seely, G. H. Williams, and D. C. Simonson. 1993. Effect of sodium on insulin sensitivity. Am. J. Physiol. 264:E730-E734.

11. DeFronzo, R. A., J. D. Tobin, and R. Andres. 1979. Glucose clamp technique: a method for quantifying insulin secretion and resistance. Am. J. Physiol. 237:E213-E223.

12. DeFronzo, R. A., D. Simonson, and E. Ferrannini. 1982. Hepatic and peripheral insulin resistance: a common feature of type 2 (noninsulin-dependent) and type 1 (insulin-dependent) diabetes mellitus. Diabetologia. 23:313-319.

13. Simonson, D. C., S. Delprato, P. Castellino, L. Groop, and R. A. DeFronzo 1987. Effect of glyburide on glycemic control, insulin requirement, and glucose metabolism in insulin-treated patients. Diabetes. 36:136-146.

14. Maguire, E. A. H., J. H. Helderman, J. D. Tobin, R. Andres, and M. Berman. 1976. Effects of arterial versus venous sampling on analysis of glucokinetics in man. J. Appl. Physiol. 41:565-573.

15. Dluhy, R. G., L. Axelrod, and G. H. Williams. 1972. Serum immunoreactive insulin and growth hormone response to potassium infusion in normal man. J. Appl. Physiol. 33:22-26.
16. Emanuel, R. L., J. P. Cain, and G. H. Williams. 1973. Double antibody radioimmunoassay of renin activity and angiotensin II in human peripheral plasma. J. Lab. Clin. Med. 81:632-640.

17. Underwood, R. H., and G. H. Williams. 1972. The simultaneous measurement of aldosterone, cortisol, and corticosterone in human peripheral plasma by displacement analysis. J. Lab. Clin. Med. 79:848-862.

18. Gordon, M. S., C. A. Steunkel, P. R. Conlin, N. K. Hollenberg, and G. H. Williams. 1989. The role of dopamine in nonmodulating hypertension. $J$. Clin. Endocrinol. \& Metab. 69:426-432.

19. Saad, M. F., S. Lillioja, B. L. Nyomba, and B. V. Howard. 1991. Racial differences in the relation between blood pressure and insulin resistance. $N$. Engl. J. Med. 324:733-739.

20. Falkner, B., S. Hulman, J. Tannenbaum, and H. Kushner. 1990. Insulin resistance and blood pressure in young black men. Hypertension (Dallas). 16:707-711

21. Manolio, T. A., P. J. Savage, G. L. Burke, K. A. Liu, L. E. Wagenknecht, S. Sidney, D. R. Jacobs Jr., J. M. Roseman, R. P. Donahue, and A. Oberman. 1990. Association of fasting insulin with blood pressure and lipids in young adults. The CARDIA study. Arteriosclerosis. 10:430-436.

22. Fraze, E., C. C. Donner, A. L. Swislocki, Y. A. Chiou, Y. D. Chen, and G. M. Reaven. 1985. Ambient plasma free fatty acid concentrations in noninsulindependent diabetes mellitus: evidence for insulin resistance. J. Clin. Endocrinol. \& Metab. 61:807-811.

23. Haffner, S. M., M. P. Stern, H. P. Hazuda, B. D. Mitchell, and J. K. Patterson. 1988. Increased insulin concentrations in nondiabetic offspring of diabetic parents. N. Engl. J. Med. 319:1297-1301.

24. Baron, A. D., and Brechtel G. 1993. Insulin differentially regulates systemic and skeletal muscle vascular resistance. Am. J. Physiol. 265:E61-E67.

25. Draznin, B., K. E. Sussman, R. H. Eckel, M. Kao, T. Yost, and N. A. Sherman. 1987. The existence of an optimal range of cytosolic free calcium for insulin-stimulated glucose transport in rat adipocytes. J. Biol. Chem. 262:1438514388.

26. Draznin, B., K. E. Sussman, R. H. Eckel, M. Kao, T. Yost, and N. A. Sherman. 1988. Possible role of cytosolic free calcium concentrations in mediating insulin resistance of obesity and hyperinsulinemia. J. Clin. Invest. 28:1848-1852.

27. Draznin, B., D. Lewis, N. Houlder, N. Sherman, M. Adamo, T. W. Garvey, D. LeRoith, and K. Sussman. 1989. Mechanism of insulin resistance induced by sustained levels of cytosolic free calcium in rat adipocytes. Endocrinology. 125:2341-2349.

28. Erne, P., P. Bolli, E. Burgisser, and F. R. Buhler. 1984. Correlation of platelet calcium with blood pressure. Effect of antihypertensive therapy. $N$. Engl. J. Med. 310:1084-1088.

29. Bruschi, G., M. E. Bruschi, M. Caroppo, G. Orlandini, M. Spaggiari, and A. Cacatorta. 1985. Cytoplasmic free cytosolic calcium is increased in the platelets of spontaneously hypertensive rats and essential hypertensive patients. Clin. Sci. 68:179-184.

30. Cooper, R. S., N. Shamsi, and S. Katz. 1987. Intracellular calcium and sodium in hypertensive patients. Hypertension (Dallas). 9:224-229.

31. Pritchard, K., A. E. G. Raine, C. C. Ashley, L. M. Castell, V. Somers, C. Osborn, J. G. G. Leadingham, and J. Conway. 1989. Correlation of blood pressure in normotensive and hypertensive individuals with platelet but not lymphocyte intracellular free calcium concentrations. Clin. Sci. 76:631-635.

32. Shoback, D. M., G. H. Williams, T. J. Moore, R. G. Dluhy, S. Podolsky, and N. K. Hollenberg. 1983. Defect in the sodium-modulated tissue responsiveness to angiotensin II in essential hypertension. J. Clin. Invest. 72:2115-2124

33. Braley, L. M., A. I. Menachery, E. M. Brown, and G. H. Williams. 1986 Comparative effects of angiotensin II, potassium, adrenocorticotropin, and cyclic adenosine 3',5'-monophosphate on cytosolic calcium in rat adrenal cells. Endocrinology. 119:1010-1019.

34. Quinn, S. J., G. H. Williams, and D. L. Tillotson. 1988. Calcium oscillations in single adrenal cells stimulated by angiotensin II. Proc. Natl. Acad. Sci. USA. 85:5754-5758.

35. Kelly, K. L., J. T. Deeney, and B. E. Corkey. 1989. Cytosolic free calcium in adipocytes. Distinct mechanisms of regulation and effect on insulin action. $J$. Biol. Chem. 264:12754-12757.

36. Levy, J., J. R. Gavin III, M. R. Hammerman, and L. V. Avioli. 1986. $\mathrm{Ca}^{2+}$ $\mathrm{Mg}^{2+}$-ATPase activity in kidney basolateral membrane in noninsulin-dependent diabetic rats. Effect of insulin. Diabetes. 35:899-905.

37. Nagy, K., G. Grunberger, and J. Levy. 1990. Insulin antagonistic effects of insulin receptor antibodies on plasma membrane $\left(\mathrm{Ca}^{2+}\right.$ and $\left.\mathrm{Mg}^{2+}\right)$ ATPase activity: a possible etiology of type B insulin resistance. Endocrinology. 126:4552.

38. Kahn, A. M., C. L. Seidel, J. C. Allen, R. G. O'Neill, H. Shelat, and T. Song. 1993. Insulin reduces contraction and intracellular calcium concentration in vascular smooth muscle. Hypertension (Dallas) 22:735-742.

39. Sechi, L. A., C. A. Griffin, E. F. Grady, J. E. Kalinyak, and M. Schambelan 1991. Insulin receptor concentration and gene expression are modulated by sodium intake in the rat kidney. J. Hypertens. 9:S212-S213. 